International Center for Public Policy

Working Paper 15-08

January 2015

Tobacco and Alcohol Excise Taxes for Improving Public Health and Revenue Outcomes: Marrying Sin and Virtue?

Richard M. Bird 

International Center for Public Policy

Working Paper 15-08

\section{Tobacco and Alcohol Excise Taxes for Improving Public Health and Revenue Outcomes: Marrying Sin and Virtue?}

Richard M. Bird

January 2015 


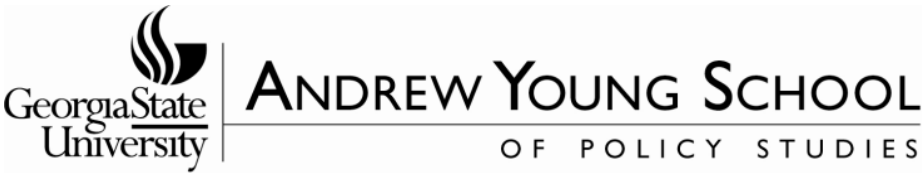

\section{International Center for Public Policy Andrew Young School of Policy Studies}

The Andrew Young School of Policy Studies was established at Georgia State University with the objective of promoting excellence in the design, implementation, and evaluation of public policy. In addition to two academic departments (economics and public administration), the Andrew Young School houses seven leading research centers and policy programs, including the International Center for Public Policy.

The mission of the International Center for Public Policy is to provide academic and professional training, applied research, and technical assistance in support of sound public policy and sustainable economic growth in developing and transitional economies.

The International Center for Public Policy at the Andrew Young School of Policy Studies is recognized worldwide for its efforts in support of economic and public policy reforms through technical assistance and training around the world. This reputation has been built serving a diverse client base, including the World Bank, the U.S. Agency for International Development (USAID), the United Nations Development Programme (UNDP), finance ministries, government organizations, legislative bodies and private sector institutions.

The success of the International Center for Public Policy reflects the breadth and depth of the inhouse technical expertise that the International Center for Public Policy can draw upon. The Andrew Young School's faculty are leading experts in economics and public policy and have authored books, published in major academic and technical journals, and have extensive experience in designing and implementing technical assistance and training programs. Andrew Young School faculty have been active in policy reform in over 40 countries around the world. Our technical assistance strategy is not to merely provide technical prescriptions for policy reform, but to engage in a collaborative effort with the host government and donor agency to identify and analyze the issues at hand, arrive at policy solutions and implement reforms.

The International Center for Public Policy specializes in four broad policy areas:

- Fiscal policy, including tax reforms, public expenditure reviews, tax administration reform

- Fiscal decentralization, including fiscal decentralization reforms, design of intergovernmental transfer systems, urban government finance

- Budgeting and fiscal management, including local government budgeting, performancebased budgeting, capital budgeting, multi-year budgeting

- Economic analysis and revenue forecasting, including micro-simulation, time series forecasting,

For more information about our technical assistance activities and training programs, please visit our website at http://aysps.gsu.edu/isp/index.html or contact us by email at gbotello1@gsu.edu 
Tobacco and Alcohol Excise Taxes for Improving Public Health and Revenue Outcomes:

Marrying Sin and Virtue?

\author{
Richard M. Bird \\ Professor Emeritus \\ University of Toronto
}

Revised; January 21, 2015

Joseph L. Rotman School of Management

University of Toronto

105 St. George Street

Toronto ON

Canada M5S $3 E 6$

rbird@rotman.utoronto.ca 


\section{Summary}

Excise taxes on alcohol and tobacco have long been a dependable and significant revenue source in many countries. More recently, considerable attention has been paid to the way in which such taxes may also be used to attain public health objectives by reducing the consumption of products with adverse health and social impacts. Some have gone further and argued that explicitly earmarking excise taxes on alcohol and tobacco to finance public health expenditures - marrying sin and virtue as it were will both make increasing such taxes more politically acceptable and provide the funding needed to increase such expenditures, especially for the poor. The basic idea -- tax 'bads' and do 'good' with the proceeds -- is simple and appealing. But designing and implementing good 'sin' taxes is a surprisingly complex task. Earmarking revenues from such taxes for health expenditures may also sound good and be a useful selling point for new taxes. However, such earmarking raises difficult issues with respect to both budgetary rigidity and political accountability. This note explores these and other issues that lurk beneath the surface of the attractive concept of using increased sin excises on alcohol and tobacco to finance 'virtuous' social spending on public health. 


\section{Tobacco and Alcohol Excise Taxes for Improving Public Health and Revenue Outcomes:}

\section{Marrying Sin and Virtue ${ }^{1}$}

Excise taxes on alcohol and tobacco have long been a dependable and significant revenue source in many countries. More recently, considerable attention has been paid to the way in which such taxes may also be used to attain public health objectives by reducing the consumption of products with adverse health and social impacts. Some have gone further and argued that explicitly earmarking excise taxes on alcohol and tobacco to finance public health expenditures - marrying sin and virtue as it were will both make increasing such taxes more politically acceptable and provide the funding needed to increase such expenditures, especially for the poor. A prominent recent instance of this approach is the success of the Philippines, after many previous failures, in increasing its excise taxes on tobacco and alcohol in 2013 - a success apparently attributable at least in part to the fact that most of the incremental revenues were earmarked for health expenditures (see Box 1).

Other countries in the region (and elsewhere) may also be considering whether they too might be able through similar packaging not only to secure more revenues but also to increase health spending. Of course, there is little new about taxing such 'sin' goods as tobacco and alcohol. Most countries have long done so. However, it is not easy to get taxing 'sin' right, as indicated by the strikingly persistent differences in the levels and structure of such taxes even in neighboring countries (see Box 2). The basic idea -- tax 'bads' and do 'good' with the proceeds -- is simple and appealing. But designing and implementing good 'sin' taxes is a surprisingly complex task. Earmarking revenues from such taxes for health expenditures may also sound good and be a useful selling point for new taxes. However, like any earmarking it raises some difficult issues with respect to both budgetary rigidity and political accountability. This note explores these and other issues that lurk beneath the surface of the superficially attractive concept of using increased sin excises on alcohol and tobacco to finance 'virtuous' social spending on public health.

To anticipate the conclusions, it turns out to be surprisingly difficult to determine the best level of alcohol and tobacco taxation for any particular country on the basis of either theory or empirical evidence. In contrast, it is much simpler to determine in principle how such taxes, whatever their level

\footnotetext{
${ }^{1}$ This revision of a paper originally prepared in July 2014 as part of World Bank support for the recent reform of 'sin' taxes in the Philippines has benefited from extensive and useful comments from a number of World Bank colleagues but of course the author is solely responsible for its contents.
} 
may be, should be structured and implemented. Unfortunately, almost no country seems to follow the indicated 'best practice' in terms of excise tax design perhaps in part because the basic problems that make it so difficult to determine the best level of such taxes seem often to be dealt with by introducing structural complexities in tax design. Finally, attractive as formally linking increased sin taxes and increases in health spending may be, there is no economic case for such linkage. Even the political case is less strong than it may seem at first glance. Because 'loose' earmarking does not in fact tie revenue and expenditure decisions closely together it amounts to little more than a deceptive illusion that may perhaps reduce rather than enhance political accountability. Earmarking sin tax revenues to health expenditures may sometimes be attractive for political reasons but it is far from a clear 'win-win' solution.

\section{The Case for Taxing Alcohol and Tobacco²}

Taxes do more than generate revenue. They also affect the allocation and distribution of economic resources in a variety of ways. Governments use taxes not only to raise revenue but also to pursue a variety of policy goals such as economic development and social justice, including improved public health. Nowhere is this dual role of taxation clearer than with respect to excise taxes like those on tobacco and alcohol. Although such taxes have long existed in most countries, their appropriate design and successful implementation raises important and difficult questions in terms of both efficiency and equity and requires close consideration of a country's administrative capacities, its economic realities, and its political environment. To what extent, and how, can or should alcohol and tobacco taxes offset external costs arising from the consumption of these products? Do such taxes unduly burden the poor? Should taxes be differentiated to take account of differences in the characteristics of both the supply and demand sides of the market? Should they be indexed? How should they be administered? Such questions may be approached in different ways, and different answers may be reached depending in part upon one's underlying 'model' of the appropriate (and feasible) role and objectives of taxing alcohol and tobacco.

\section{The Public Health Approach}

\footnotetext{
${ }^{2}$ This discussion relates only to special (excise) taxes on these products. In addition, such products should be subject to the standard rate of VAT with excise tax (like any import duty) being included in the VAT base.
} 
Consider first what may be called the 'public health' approach to such taxes. This approach essentially views taxation as one way to cope with the social problems attributable to the consumption of tobacco and alcohol. The aim, as Crooks (1989, pp. 31-32) notes with respect to alcohol taxes, is "... to limit the harm caused by alcohol consumption, by reducing (or at least preventing from rising) the overall average consumption per person." The principal objective of taxation in the context of public health intervention policy is thus to reduce the aggregate volume of consumption of harmful products in order to save both individuals and society from the consequences of poor individual consumption decisions.

This approach is now widely accepted with respect to tobacco. However, perhaps because in most countries more people now drink at least occasionally than smoke, considerable time and effort has been spent on trying to fine-tune this approach to deter 'excess' consumption of alcohol without unduly penalizing those who drink only moderately. Unfortunately, even in the most information-rich developed countries, we are still far from fully understanding the extent to which taxes (higher prices) may discourage young drinkers and smokers (or 'binge' drinkers), the extent to which such discouragement reduces the long-term social problems arising from addiction, or how to weigh such gains against any losses arising from affecting the consumption choices of everyone. Nor do we yet adequately understand the extent to which from a social point of view differential taxation of different forms of these products - whether beer, spirits or wine or different ways to deliver nicotine such as vapor systems - may induce users to shift to less (or perhaps more?) harmful forms of consumption.

On the whole, perhaps the main message for developing countries from the extensive empirical literature on harm-reducing taxation is simply that if the objective is to improve public health outcomes, the main objective of tax policy should be to discourage aggregate consumption of these products by imposing higher taxes on them than on other products. As Cook (2007) shows with respect to alcohol taxes in the United States, even developed countries have found it difficult to establish and maintain a given level of effective taxation on harmful goods. Moreover, as Cnossen (2008, p. 534) noted in a study of alcohol taxation in Europe, “...making moderate drinkers even more moderate can reduce the probability of transition to heavy drinking." That is, even if some welfare may be lost by forgoing possible health benefits of (very) moderate alcohol consumption, this loss may be more than offset by reducing the number of heavy drinkers. Of course, since as yet no one attributes any benefit to moderate tobacco consumption, this argument applies even more strongly in the case of tobacco. 
The social costs associated with alcohol and tobacco consumption that motivate the health argument for taxing these products have been much studied. In both developed and developing countries a wide range of research in economics, sociology, psychology, and medicine documents the adverse impact of tobacco consumption and excessive alcohol consumption on health status, as well as the impact of the latter on vehicle accidents, work effort, and family well-being. Since both smoking and excessive drinking definitely damage the health of those who indulge and -- especially in the case of the latter -also the well-being of society more generally, less is clearly better than more, so if special taxation of these products result in less consumption, society is better off. Apart from this simple and important message, however, the public health model offers surprisingly little guidance to alcohol and tobacco tax policy in part because even if countries are clear with respect to the precise objectives of such policy, which is seldom the case, they almost never have sufficient information about critical parameters to be able to construct any more refined sin tax policy.

\section{The Economic Approach}

Smith (2005) suggests with respect to alcohol that what he calls the 'economic' approach may provide a clearer guide to policy. The economic approach differs from the public health approach in two major ways. First, it takes a narrower view of the social costs of alcohol and tobacco and focuses on the externalities imposed on society in general rather than on total social costs, including those imposed on direct users. If someone drinks or smokes (or both) too much and dies sooner than he or she otherwise would have done - for example, from tobacco-induced illness or by crashing a motor vehicle while drunk - it may be a tragedy, but it is not an externality. If, however, a drunken driver kills a passer-by or children die sooner because they are brought up by adult smokers, then it is both. The economic approach is thus narrower than the public health approach in the sense that it focuses on externalities rather than social costs broadly defined to include those incurred by consumers themselves. As a result, as Cnossen and Smart (2005) demonstrate, this approach tends to suggest that relatively lower taxes are socially optimal than does the public health approach. On the other hand, the economic approach is broader than the public health approach in several respects: for instance, it pays more attention both to the equity and administrative aspects of taxes on tobacco and alcohol and to the relative efficiency of such taxes in raising public revenues.

Since economists, like public health specialists, are human they too are often tempted to try to improve the lives of others. In economic terms, however, with important exceptions such as the possible need to deter irrational decisions by the rash or ignorant young, the economically relevant externalities arising 
from consumption of addictive goods are not the costs imposed on the user but only those that are imposed on others. This position is arguable: it assumes, for example, that individuals who drink or smoke make rational choices and can and should bear the consequences their actions may bring on themselves. There is a large literature about "rational addiction," the interplay of psychological, physiological, and economic factors that lead to addiction and its consequences that is not discussed here (Gruber 2010). However, apart from the special case of the young (discussed later), stopping people from harming themselves seems unlikely to be a high-priority policy goal for developing countries that already have more on their plates than they can handle with respect to devising and implementing good tax policy.

What is considered to be a socially relevant externality in any setting obviously depends in part on context-specific cultural and institutional factors. In general, however, if one assumes - as economists do as a rule -- that people are relatively rational in the sense that they balance such potential costs to themselves against the pleasure they obtain from drinking and smoking, it seems not unreasonable to consider any suffering they may endure as a result of their choice to be their problem and not society's. To show how assumption-dependent analysis of this subject is, note that one can treat costs imposed on family members in two very different ways. If the full effect of these costs is taken into account in the user's utility function - if, so to speak, he feels his family's pain as his own - then there is nothing 'external' about such costs and (from a strictly economic perspective) no need for social intervention in the individual's decision to smoke or drink. If, however, users do not care about the well-being of members of their families, then costs imposed on them are externalities no different than those imposed on anyone else. Similarly, analysis is also highly institution-dependent: what is an 'externality', for example, may depend in part on how public health care is financed.

Even if the externalities (or, if one takes the public health approach, the total social costs) associated with alcohol and/or tobacco consumption are as large as some argue, the correct policy prescription may be not simply to tax these products but to ban them. Most countries go some way down this path in the sense that they have in place a wide range of important regulatory policies with respect to alcohol and tobacco. For example, restrictions on who is allowed to produce and sell these goods and on the kind and type of goods that may be marketed as well as restrictions on who can buy and consume them, where and when they can be bought, and where and when they can be used are all to be found, to differing extents, in many countries. The extent, nature and effectiveness of such regulatory policies 
and the extent to which they may be considered to complement or substitute for taxation are important factors that should be taken into account in designing alcohol and tobacco taxes (see Box 5 below).

\section{The Political Economy Approach}

However the economic (or public health) calculus works out, one important reason that taxes on tobacco and alcohol are always attractive to policy makers is as a relatively acceptable means of mobilizing revenue. The negative image (and reality) associated with consumption of these products makes it relatively easier to sell such taxes to the public than other taxes such as general income and sales taxes. Most people seem to accept alcohol and tobacco consumption creates real social costs which justify relatively heavy taxation on these products (Brezis and Marans 2010). Indeed, in recent years the social acceptance of smoking in particular has declined so much that even smokers often accept that they should pay a fiscal penalty for indulging. Taxes on alcohol and tobacco may thus be presented as not only increasing revenues but doing so by taxing 'bads', correcting socially inappropriate consumption decisions, and compensating society for some of the costs arising from the unwise consumption of these products.

Although these arguments alone have sufficed to achieve substantial levels of excise taxation on these products in many countries, to put frosting on the cake governments sometimes go further and promise that the increased revenues will be explicitly directed (earmarked) to increased expenditures on health. In the recent Philippine case (Box 1), for example, the government demonstrated its sincerity in this respect by establishing an accounting and monitoring system to ensure that the funds actually flow to the designated purpose. By doing so, not only was the alliance between 'taxers' (the Ministry of Finance) and 'spenders' (the Ministry of Health) presumably strengthened to some extent but the public was given more reason to believe that increasing taxes aimed at discouraging sin would be accompanied by an expansion of virtuous public expenditures.

\section{The Level of Excise Taxes}

The most important determinant of both the revenue and the health effects of any sin tax is its effective rate. Increases in rates up to some point will increase revenue; similarly, increasing rates up to some point will increase the health (and other social) benefits resulting from such taxes. However, these two key rates - the revenue-maximizing tax rate (RMTR) and the socially optimal tax rate (OTR) are unlikely 
to be the same. In addition, the important political economy aspects of sin taxation suggest that there is yet another critical rate, which might perhaps be called the politically 'acceptable' tax rate (PATR).

Calculating the RMTR for any excise is in principle relatively simple: maximize a revenue function, subject to assumptions about the elasticity of supply and demand. In the simplest case, for example, assume that there is only one good, that supply is infinitely elastic, and that the demand curve is linear. In this case, the revenue maximizing tax rate for an excise tax, $t^{*}$, is equal to $-1 / 2 \eta$, where $\eta$ is the own price elasticity of demand for the taxed good. More generally, the revenue maximizing rate is a more complicated function of demand and supply elasticities. For example, in the two-good case (two close substitutes) when elasticities are constant but the elasticity of supply is not infinite, the revenue maximizing rate is approximately equal to $(\eta-\varepsilon) /(2 \eta \varepsilon-\eta)$, where $\varepsilon=$ the price elasticity of supply. The basic problem in applying this approach is that consistent or reliable estimates of these elasticities are seldom available in developing countries and that such estimates are in any case highly sensitive to many factors - industry structure, macroeconomic conditions, how the revenue is spent, etc. ${ }^{3}$

Calculating the optimal externality-correcting excise tax rate (OTR) - the rate needed to internalize the net social costs of externalities associated with consumption -- is conceptually and empirically similar but considerably more complex (O'Donaghue and Rabin 2006). Such calculations depend not only on the data available but also the plausibility of the many assumptions on which they are necessarily based. For example, a rigorous analysis of the revenue efficiency of an excise system in Thailand in terms of the MCPF (marginal cost of public funds) in Dahlby (2008) demonstrates clearly how difficult it is to apply and interpret this approach in the context of a developing country where there is considerable uncertainty about such key parameters as externalities, addiction, market structure, smuggling, intersections with other tax bases (and regulations), and 'tax exporting' (to tourists).

Although, as World Bank (2014) has recently shown with respect to the Philippines, such exercises are nonetheless useful in developing a more consistent and useful analytical framework to guide and assess excise tax policy, in the end most expert analysts have concluded that even the best studies of the optimal rate and structure of taxes on alcohol and tobacco in data-rich developed countries can provide only rough guidance and few clear answers to policy-makers seeking to improve excise systems. Recently, for example, the extensive Mirrlees Report on the reform of the UK tax system, after considering the evidence summarized in Box 3, concluded that because there are good reasons for

\footnotetext{
${ }^{3}$ For an example of RMTR calculations for alcohol excises in Africa, see Bird and Wallace (2010). As Usher (2014) shows, however, such calculations are subject to so many qualifications that they provide little useful guidance.
} 
imposing additional taxes on tobacco and alcohol and no good reasons to change either the level or the structure of the existing taxes, the UK should keep on doing what it was doing with respect to 'sin' taxes (Institute for Fiscal Studies 2011). In short, about the best this careful review of the UK tax system could come up with -- since the RMTR is too crude and simple to take seriously in tax design, and the OTR is, even in the UK, too difficult to calculate reliably and likely too dependent on controversial assumptions to be widely persuasive -- was in effect to accept the structure that had been generated over time through the workings of the political system -- the PATR, as it was labeled above.

In reality, excise tax rates are usually set at levels and in ways that policymakers consider to be politically acceptable. Often, as Haavio and Kotakopi (2011) argue, the result is that the rate set is generally lower than the socially optimal level, although, as Cnossen and Smart (2005) note, this may not always be the outcome. Excise tax structures in most countries are generally different from any of the conceptually ideal taxes postulated in the literature, in part for reasons often rooted in national social and political factors. One result is that cross-country harmonization is difficult, though perhaps also less necessary, as discussed further below. Another result is that although excise tax rates often change, usually for revenue reasons, there is little evidence of convergence across countries or over time with respect to either an 'optimal' structure or a common structure (Box 2). Tax rates differ widely from country to country, and indeed over time within any one country, and in general bear little relation to even the simple goal of revenue maximization let alone to any reasonable estimate of either the social costs or the externalities associated with the consumption of alcohol and tobacco. As a rule, how much and how these products are taxed is better explained by history, revenue needs, and the need to satisfy political constituencies than by the answers suggested by economic analysis or the importance attached to such objectives such as improving public health or maximizing social welfare.

\section{The Structure of Excise Taxes}

\section{Specific or Ad Valorem Rates?}

Specific taxes are levied as a flat amount per physical unit, say per stick or package for cigarettes or unit of alcohol or liter for alcoholic beverages. Ad valorem taxes are a percent of the price (wholesale or retail) of the good. Which is better? As usual in economics and life, there is not always a simple and clear answer. Each approach has its merits and problems, and the best trade-off between the two may 
differ from country to country, from tobacco to alcohol, and even from item to item within each category. ${ }^{4}$

One important advantage of specific taxes is that they simplify administration. The tax inspector only needs to be able to count, and does not have to worry about the often troublesome issue of valuation. In addition, since one objective in taxing alcohol and tobacco is to discourage consumption, imposing the tax on the target - the tobacco or alcoholic content - and not the value of the product makes sense. Whether specific or ad valorem rates (or some combination of the two), are used, as Box 4 suggests, additional questions must be answered with respect to the precise tax base to which the rates are applied. The most important problem with specific rates is that such taxes have generally proved to be "sticky" - difficult to change - in the face of inflation, with the result that real revenues tend to decline over time, thus decreasing both the public health effectiveness of the tax and its possible efficiency advantage as a revenue raiser compared to other possible revenue sources. ${ }^{5}$ Although it is easy to circumvent this problem by including a provision in the law requiring annual adjustment in specific excise tax rates in accordance with changes in the general level of prices, surprisingly few countries have taken this obvious step to strengthen both the revenue and health effects of excises on alcohol and tobacco. One reason for this reluctance may perhaps be because if the rate of inflation is high it is also likely to be variable, and frequent revisions in specific duty rates can create significant undesirable incentives for anticipatory stock-building, a matter of evident concern in the recent Philippine reform (World Bank 2014).

In addition, uniform specific taxes also discriminate against relatively cheaper products since tax as a proportion of final price constitutes a larger proportion of lower prices. For this reason such taxes are often applied at different rates to lower-priced products or varieties of products (e.g. kretek cigarettes in Indonesia, or, in some countries, beer as opposed to spirit) that are assumed to be consumed more by low-income people and/or perhaps produced by smaller, more labor-intensive, or domestic rather than foreign enterprises. Such classified tax regimes make tax administration considerably more complex.

\footnotetext{
${ }^{4}$ Countries sometimes impose 'mixed' or 'composite' rate structures with both specific and ad valorem rates, sometimes on different products, sometimes on the same product, and sometimes (as in Thailand) with the specific rate serving in effect as a minimum tax. Depending on the (always critical) details, such systems in effect combine in various ways the advantages and disadvantages of the two basic approaches discussed here.

${ }^{5}$ That such taxes are efficient is not always evident: in Thailand, for example, Dahlby (2008) found that the MCF for the alcohol and tobacco excises were considerably higher than for fuel excises or the VAT, although, as his analysis shows, such calculations are very sensitive to a series of inherently rough estimates and assumptions about a variety of institutional and technical issues, as well as about the always disputable issue of distributional weighting.
} 
Determining the tax base of a specific tax can also sometimes be a complicated matter particularly with respect to alcohol when different varieties are commonly consumed in different ways by different groups. Finally, as Keen (1998) stresses, since specific taxation is based on some physical characteristic of the product, the tax may not tax the value of the alcohol to the consumer. While this is less of a concern when, as is common, other taxes like VAT are imposed on the full value, an excise that does not tax features such as packaging or convenience of availability may lead consumers to demand and producers to supply more such untaxed amenities, which seems unlikely to be a sensible use of scarce resources in developing countries.

Ad valorem taxes, although less adversely affected by inflation and often imposed for distributional reasons (as discussed below), have their own problems. Since such taxes are more complicated to administer, sometimes administratively-determined prices are used as the tax base thus converting the ad valorem tax to a specific tax. In addition, ad valorem taxes favor cheaper products, which may be considered undesirable if, for example, lower prices mean lower quality and hence perhaps more health or other risks. Moreover, ad valorem taxes in effect introduce a multiplier effect in the price of the good. For a producer to increase the net-of-tax price by a given amount, the price charged to the consumer must be increased by $1 /(1-t)$ where $t$ is the ad valorem tax rate charged on the good. This multiplier effect may perhaps discourage improvements in the quality of the taxed good since the producer must increase prices by more than the value of an improvement in order to break even on the investment. On the other hand, if producers lower prices more when taxes are imposed in ad valorem form, presumably consumption would be increased with harmful health effects particularly if lowerincome consumers have a higher price-elasticity of demand. In this case, however, as World Bank (2014) suggests may be the case in the Philippines and Bosch and Koch (2014) show for South Africa, it is not impossible that increasing taxes and hence prices will discourage lower-income consumers most and hence end up reducing the regressivity of the tax as a whole. However, the distributional issue is not that simple. Not only is the incidence of excise taxes of little direct interest to those who do not consume the taxed products, but even for smokers and drinkers excise taxes on tobacco and alcohol are most regressive when assessed in terms of current incomes, much less so in terms of spending, and even less so when viewed from a lifetime perspective. Indeed, in the case of the UK, spending on alcohol as a percent of total spending is actually progressive for the first four expenditure quintiles (Crawford, Smith and Keen 2010). 
As with setting the appropriate level of excise taxes, the main lesson one learns from examining the empirical evidence on the differential effects on prices, consumption, and health of specific and ad valorem taxes is that the evidence supporting most proposed or actual differentiations is neither strong nor easy to interpret from a policy perspective. In practice, so little is certain about tax effects on prices and quality even in developed countries that in practice the choice of specific or ad valorem rates usually comes down to how one weighs the administrative advantages of the former relative to the potential revenue loss in the face of inflation unless politically unpopular changes in nominal tax rates are made regularly. On the whole, international experience suggests that the specific tax approach is probably the best way both economically and administratively to impose relatively high taxes on alcohol and tobacco. The specific approach also best fits the public health perspective. However, periodic review and revision of specific rates is essential to ensure that both revenue and social objectives continue to be achieved over time.

\section{Uniform or Differentiated Rates?}

Tax rates are usually the focus of public discussion. However, an equally or even more critical question is the base to which they are applied. The public health literature suggests that the appropriate tax base for alcohol excise taxes is the alcohol content of beverages subject to tax (see Box 4). The definition of alcohol content is in some countries specifically related to percent alcohol by volume. In others, however, different rates apply to different types of alcohol: in Europe, for example, most countries treat units of alcohol delivered in the form of beer and wine quite differently, apparently largely on cultural grounds, while applying the highest rates to alcohol in spirits (Cnossen 2008). Countries where beer is the 'drink of the people' and wine is something that only the rich drink may justify differential taxation on distributive grounds. Countries in which wine is a normal accompaniment to food and 'binge' drinking is associated with spirits may be more likely to tax the former more lightly and the latter more heavily than warranted in terms of their respective alcohol content as usually consumed (that is, taking into account that most spirits are mixed with other liquids when drunk). ${ }^{6}$ If spirit drinkers are seen as more likely to turn to illicit (and possibly even unsafe) sources to their alcoholic 'fix', however, such differential taxation may not seem advisable (Crawford, Keen and Smith 2010); similarly, if beer is the drink of choice of the young and/or binge drinkers it should be taxed at least as heavily as spirits (Cook 2007). In the absence of solid knowledge about many of these matters, as with the more technical

\footnotetext{
${ }^{6}$ As is true of most attempts to 'fine tune' excise taxation, however, little evidence supports any conclusion except that binge-drinkers (of any age) are unlikely to be highly responsive to increased prices or taxes (Nelson 2014).
} 
questions of quality and price mentioned earlier, in the end policy-makers even in developed countries can do little more than balance as carefully as the evidence permits the various conflicting considerations that may affect the decision of how to structure taxes on alcohol. Again, there is much to be said for the simplest solution of imposing a uniform tax related to alcohol content.

While such differentiation is less important when it comes to tobacco products (cigarettes, cigars, chewing tobacco, etc.), differentiation in the treatment of cigarettes is found in a few countries such as Indonesia, where, presumably to encourage employment and local growers, significantly lighter taxes are imposed on cigarettes produced (especially by hand) in small local factories from locally-grown tobacco and sold at relatively low prices. Similar features may be found in other countries: in some U.S. states, for example, where tobacco growers are important, employment and other concerns have kept taxes low, and India has long favored local and hand-made products in its tobacco tax policy in part for employment reasons. Some countries have attempted to introduce explicit progressivity into the rate structure by imposing ad valorem or price-based specific taxes. As with many tax differentials intended to achieve non-fiscal objectives, however, none of these features appears particularly effective in achieving the stated objectives and all tend both to complicate administration and reduce the extent to which the revenue and health objectives of tobacco taxation are achieved.

Another possible argument for multiple rates - the 'optimal tax' argument - is to reduce the efficiency cost of taxation by taxing products with few substitutes and lower price elasticities more heavily. As noted earlier, however, it is difficult to determine exactly what excise structure is optimal in this sense even in developed countries. Although more knowledge is better than none, and some knowledge can, as World Bank (2014) shows, be helpful in shaping some aspects of excise tax policy, when conceptual and data problems are combined with the administrative complexities to which multiple rates give rise, most developing countries seem well advised to keep their excise systems as simple and uniform as possible - for example, by taxing cigarettes on the basis of the number of units. ${ }^{7}$

\section{Efficiency and Equity}

In theory, the effects of any tax on equity and efficiency - a term that encompasses both economic efficiency (the impact of taxes on the decisions of producers and consumers) and administrative and

\footnotetext{
${ }^{7}$ For a useful review of different possible bases for tobacco taxes, as well as a review of the policy and administration of such taxes in a number of Asian countries a few years ago, see Sunley (2007).
} 
compliance efficiency (how costly it is to administer and comply with the tax system) -- depends on many other factors. Among the relevant factors are incomes, tastes and preferences (which influence the acceptability of substitute consumption goods and the distribution of the burden of taxation); the structure and technology of production (which affect the behavior of suppliers as well as production of substitutes and the extent and nature of adjustments in output prices; the regulatory system (which affects tax administration and the acceptance of the tax regime); production technologies; and the performance of the tax administration (which may encourage or discourage tax evasion and avoidance and thus alter the real effects of the tax).

Increasing taxes on alcohol and tobacco is usually regressive, particularly when measured against current incomes, because it imposes a relatively higher tax burden on consumers of these products with lower incomes than those with higher income. ${ }^{8}$ The extent to which excise taxes are shifted forward to consumers varies with macroeconomic conditions, the structure of the relevant industries, and, of course, the short-term and long-term elasticities of demand and supply. However, the empirical evidence generally supports the conclusion that such taxes are largely shifted forward to consumers (Chiou and Muehlegger 2014). One reason many countries introduce complex structures including such features as ad valorem rates and different levels of specific tax on different types of alcoholic beverages and on cigarettes sold at different price levels is presumably to reduce such regressivity. Imposing inherently regressive taxes in what seems to be a more progressive way may perhaps make such taxes more politically acceptable. However, such details are unlikely to have sufficient effect on the distributional impact of excises on alcohol and tobacco to be worth the additional complexity and cost that differential rates invariably add to the system. Moreover, it seldom makes sense to appraise the distributional impact of any particular tax change as if each tax stands alone. Any one tax is only part of the broader fiscal (and regulatory) system that modifies the distribution of income and wealth; presumably, those concerned with the distributional effect of policy should be more interested in the final result than in the details of how it is reached.

Both the poor and non-poor will presumably reduce their consumption of alcohol and tobacco when taxes on these products are increased. In the best of all possible worlds, if as some evidence suggests, the poor are sufficiently more price-sensitive than the rich they may even reduce their expenditure on such goods so much that they will end up no poorer than before. Indeed, they may even be not only

\footnotetext{
${ }^{8}$ As noted earlier, measured regressivity is lower when measured against spending rather than income deciles or over a longer (lifetime) period.
} 
presumably healthier but even relatively better off in distributional terms. For example, a recent study in South Africa, where $40 \%$ of the cigarette tax burden is estimated to be borne by the poorest $20 \%$ of the population, found that an increase in the tax actually reduced the burden on this group and concluded that "...not only are tobacco taxes an important instrument in the fight for improved public health, they are also a useful instrument in the fight against poverty" (Bosch and Koch 2014, p. 3). On the other hand, another recent study found that the deeper empirical consideration of how people responded to such tax changes possible with more detailed U.S. data casts a cloud on this happy conclusion. In the short term, Chiou and Muehlegger (2014) find that increasing cigarette taxes definitely reduced consumption especially of cheaper cigarettes, both because of stockpiling before the expected increase and substitution after it took place. However, the short-term and long-term effects of the tax increase were markedly different. After the initial post-tax substitution of lower for higher priced cigarettes, the 'flight to quality' stressed in the literature (Barzel 1976) ensued as the consumption of pricier cigarettes rose while that of cheaper cigarettes declined. Moeover, the evidence shows that because the shift was not only towards more expensive cigarettes but to cigarettes higher in tar, nicotine and carbon monoxide, so that the net result of increasing the tobacco tax was to increase rather than reduce the negative effect on health outcomes (Chiou and Muehlegger 2014).

However, this analysis does not consider the possibly offsetting effect of higher taxes on discouraging beginning smokers. Taxes that discourage people from taking up unhealthy habits in the first place may not be regressive across the population as a whole if one takes into account their effect in reducing the level of addiction: that is, such taxes may not only improve health outcomes for the population as a whole but also reduce both poverty and ignorance. Without going further into the 'rational addiction' literature (Gruber 2010), as before the main conclusion that seems to emerge from the partial and conflicting evidence on all these matters is that it is unlikely to make sense to clutter up the tax structure with complicated excise taxes aimed at e.g. imposing minutely higher taxes on a few people who drink imported whiskey or smoke expensive cigars or delivering a small nudge to deter potential abusers by raising the price of such 'introductory' delivery systems as e-cigarettes or wine coolers. Detailed excise tax policies targeted to refined equity aims, like those aimed at achieving an empirically (and usually politically) unsupported degree of economic efficiency, may all too easily divert attention from the two main, and achievable, objectives of good excise policy: to reduce the consumption of harmful goods and to raise revenue in a relatively efficient way. 


\section{Taxation and Regulation}

Taxation and regulation are sometimes complementary and sometimes substitutes. Many countries impose regulatory policies such as age limits for the sale of alcohol and tobacco as well as special penalties for those who drink and drive or sell or use these products improperly (see Box 5). The effectiveness and effects of such regulations need to be considered in designing alcohol and tobacco taxes. Under-aged drinkers and smokers pay the same taxes as adults, for example, but some evidence suggests that tax increases may have more of a deterrent effect on the young since they are more pricesensitive (Grossman et al., 1994). Does this imply that higher taxes should therefore be imposed on everyone? Or does it instead suggest the desirability of tighter enforcement of age restrictions? If taxes are high enough, can regulations be eliminated, or vice versa? How best can regulations and taxes work together to achieve such policy objectives? What matters from a public health perspective as from a distributive perspective is not the impact of any one policy - such as excise taxation - but the joint impact of all policies - taxation, information and education, and regulation -- as these policies are actually implemented (see Box 5). In principle, the right combination of tax and regulatory policy is likely to produce better results than either policy will on its own (Christiansen and Smith 2009).

However, the basic problem for most developing countries is that they have to design their tax and regulatory policies without knowing what they really need to know about elasticities, externalities, and markets in order to do it right. The best way to improve policy outcomes may be to help such countries improve their knowledge of such things rather than to tell them they 'must' or 'should' do this or that. Consider, for example, the recent assertion that 'best practice' presumably everywhere is to impose a tobacco tax that is at least $70 \%$ of the retail price (WHO 2011). What affects consumption is the relative price of different products (e.g. smuggled or illicitly-produced vs. legal and taxed), not the extent to which that price reflects taxes. One may argue that the evidence supports higher than average taxes on alcohol and tobacco products. One may also argue, as noted earlier, that simpler and more uniform taxes are probably better, especially in countries with relative weak enforcement structures, than more complex and differentiated taxes. However, as Crawford, Keen and Smith (2010) emphasize, even in the relatively uniform context of the EU, it makes no sense to assume that either the external costs of sin or the impact of taxes on reducing harmful consumption are the same in every country, let alone that either is appropriately reflected in the proposed '70\% solution.' More uniform excise tax policies across countries in the sense of placing a floor under tax rates (not as a percent of final price but as a minimal estimate of external costs) might be useful in deterring potentially harmful 'races to the bottom' in the 
name of tax competition. But it is unlikely that setting such a target rate (as a share of final price) for every country can make sense unless all relevant conditions affecting tax incidence and effects are, most implausibly, assumed to be the same. Simple quantitative targets may be easy to understand, and may perhaps prove useful in spurring countries into re-examining and strengthening their excise tax systems; but they do not necessarily provide a good guide to sound policy for any particular country. ${ }^{9}$

\section{Administration}

The main administrative problem with excise taxes on alcohol and tobacco is simply to collect the taxes due. This task is relatively simple when the taxes are imposed on large domestic producers and imports. However, the extent to which illicit products, whether smuggled or illegally produced in the country, may be substituted for taxed products needs to be carefully considered when setting excise tax. Some countries have encountered problems with the illicit production of various types of 'home' brews and spirits: such production is usually small-scale in nature but it may also produce deleterious effects on health and even death. ${ }^{10}$ In many countries, smuggling across borders has been a persistent problem with both cigarettes and highly taxed alcohol. Countries need to pay attention to the level of prices charged in neighboring countries when they set their excise rates. As Cooper (2007) notes, the 'affordability' of products (as measured by the share of income required to purchase a given quantity) may provide a useful measure of the extent to which increasing excise taxes may make administration more difficult by inducing more illicit trading. However, unless demand is completely inelastic and administration is so weak that access to illegal (unregulated) sources of supply is virtually unlimited and costs less than the tax, tax-induced reductions in 'affordability' are most unlikely to result in so much smuggling that neither revenue nor health will improve after a tax increase.

Nonetheless, no country can set its tax rates in isolation from those applied in other jurisdictions to which the potential domestic consumers have access. In the European Union (EU), as in North America, there is considerable evidence that both legal cross-border shopping and smuggling and other forms of tax evasion are encouraged by sizable differences in tax burdens. As mentioned earlier, the EU has established a uniform base for tobacco taxes. It has also established a basic 'floor' rate for both alcohol and tobacco taxes. Floor prices may serve to check on the downward pressure that the cross-border

\footnotetext{
${ }^{9}$ For a related argument, see International Tax and Investment Center (2014).

${ }^{10}$ Bird and Wallace (2010) note that in some instances home production may have some cultural significance as well as effects on employment that need to be taken into account.
} 
option would otherwise exert on the domestic rates imposed on these goods, especially if the floors were high enough to reflect the (average) external costs of their consumption. However, the present EU floors appear not only too low for this purpose but have proved almost impossible to alter (Crawford, Keen and Smith 2010). On the whole, neither the EU experience nor the extensive literature on the subnational taxation of alcohol and tobacco in the US and Canada suggests that it is easy for economic groupings like those existing or emerging in many developing regions of the world to develop viable regional solutions to such problems or that reasonable interjurisdictional differences in rates are unsustainable in the absence of uniform or harmonized regional solutions.

As discussed earlier, the best form of excise taxation is a uniform (indexed) specific tax based on the number of units - cigarettes or units of alcohol as the case may be. Such taxes are not only simple to administer but generally most productive in terms of both revenue and health outcomes. Nonetheless, many countries impose different tax rates on different product groups or have ad valorem taxes or a mixed specific and ad valorem system, in some cases (as in Thailand) with the specific rate being used as an alternative minimum tax when it imposes a higher tax than the ad valorem system would impose. Such approaches complicate administration, making it simultaneously more costly and less likely to be uniformly effective. Some of these complicating features are, intended to achieve equity aims although, as noted earlier, it seems unlikely that any gains achieved are worth the additional cost and complexity. Others are intended to protect such domestic activities as tobacco farmers, producers of cigarettes and alcoholic beverages or spirits, and employment in these sectors. Again, however, the administrative complexity and economic inefficiencies arising from such differentiation are likely to offset any social gains from these policies. If countries wish to protect domestic industries, tariffs are a more transparent, effective, and less distorting way to do so; if they want to encourage employment, industry-specific tax favoritism is one of the least efficient ways to do so.

The main problem with specific excise taxes is inflation. Unless rates are periodically adjusted to account for price level changes, the real effective tax rate will automatically decline, thus reducing both revenue and the beneficial health outcomes that would otherwise accrue. The answer seems obvious: provide for regular - annual, even quarterly - automatic adjustments in specific rates to ensure that the effective tax rate remains constant. ${ }^{11}$ Since few countries do this the general pattern of effective excise

\footnotetext{
${ }^{11}$ For some years, both Australia and New Zealand have indexed excise tax rates, generally adjusting rates according to changes in in the consumer price index (CPI). New Zealand makes such adjustments annually, but Australia usually does so twice a year. Interestingly, in 2014 Australia began to adjust its tobacco taxes not by
} 
rates is to decline over time for some years until nominal rates are changed - usually after considerable political fuss. Introducing such an adjustment mechanism is perhaps the simplest and one of the most important improvements that countries can and should make in taxing such products as tobacco and alcohol. Unfortunately, even when, as in the recent Philippine reform, an adjustment mechanism is included in the law it is often unrelated to the rate of price inflation. The uniform annual adjustment of 4\% established in the Philippines is definitely better than nothing, but in some cases it may be too much and in others too little: it is most unlikely ever to be just right.

The importance of good administration has long been as obvious to those concerned with tax policy in developing countries as has its absence. Initially, the effective administration of high-rate excise taxes depended on establishing an adequate system to control the physical commodity. Producers and sellers of excise products were registered and their premises policed so that no goods were shipped without paying tax, just as import duties are typically paid at the point of importation before the product is released from border control. Another type of physical control, useful only for specific taxes, was to apply a seal over the cork (or a strip seal or 'stamp' over the cap or around the package) to signify that the tax had been paid. Such systems are not cheap to administer and frequently resulted in both corruption and evasion. Increasingly, however, excise taxes, like other taxes, are administered primarily through control of accounting records, supplemented by such technological aids as 'digital stamps. ${ }^{.12}$ These recent developments may be useful in many cases. However, the main lesson from experience is that when excise taxes are increased not only should their structure be kept as simple as possible to make administration manageable but that in many cases the basic excise tax administration may also need strengthening if the revenue (and health) objectives of such increases are to be achieved.

\section{Is Earmarking a Good Idea?}

The dual objectives of 'sin' taxes are in a sense inherently contradictory: one target, increased revenue, is more likely to be achieved if the consumption of the taxed products increases while the other, improved health outcomes, requires that consumption be reduced. Those who support increasing excise taxes on alcohol and tobacco taxes on health grounds often argue that the proceeds of such taxes

changes in the CPI but instead by changes in a wage index (average weekly ordinary time earnings), apparently in part because using this index increased the size of the adjustment.

${ }^{12}$ Digital stamping encrypts information on a stamp or even directly on a container and permits authorities to authenticate and verify the embedded information in the field with simple handheld instruments. 
should be earmarked to finance health expenditures -- especially for the poor, who are usually most impacted by such taxes -- or perhaps such other health-focused activities such as anti-tobacco education and advertising. While many countries with high excises do not earmark the revenues from these taxes, there are some good reasons for such arguments. Although, as discussed earlier, it is not as simple as some seem to think to design the 'right' taxes on alcohol and tobacco, there is much to be said for rationalizing and increasing such taxes on both revenue and health grounds. Moreover, increased expenditure on public health, especially for low-income persons, is also a generally good idea in developing countries in terms of both equity and increasing productivity. The idea of tying increases in 'good' taxes that themselves have beneficial health benefits to expanded 'good' expenditure on improving low-income health thus seems both logical and attractive. Equally importantly, since the presumed progressivity of expanding health spending compensates at least to some extent for the regressivity of the taxes, tying the two together may make the tax reform more politically acceptable, as the recent Philippine reform has demonstrated.

Other instances of earmarking excises on alcohol and tobacco, not always for health purposes, may be found in the region. For example, Indonesia allocates a $2 \%$ excise for health to local governments and since 2014 has also earmarked a 10\% tax for regional governments. Thailand allocates some alcohol and tobacco taxes not only to health but to local provinces and even for public TV broadcasting. Korea earmarks part of the alcohol excise to education, and also imposes several special earmarked taxes on tobacco including one collected by the Ministry of Health and Welfare with the revenue earmarked to finance public health information. Taiwan also earmarks some tobacco tax receipts to a variety of medical services including health promotion. Cambodia even earmarks some excise taxes for public lighting. ${ }^{13}$

Nonetheless, despite the frequency with which such arguments are made by proponents of increasing health expenditures as well as by politicians attempting to make tax increases more palatable by associating them with such expenditures, in reality few countries earmark revenues from taxes on alcohol and tobacco taxes to health-related activities. One reason is simply because, apart from the short-term political push --perhaps essential in some cases-- such earmarking may provide for excise tax reform, there is no long-term rationale for tying this source of revenue to health expenditures -- let alone to such completely unrelated activities as public lighting and public TV, as has been done in other ASEAN countries (Box 2) or to education and local finance as in Korea (Bird and Jun 2007).

\footnotetext{
${ }^{13}$ This information comes from the sources cited in Box 2 as well as ITIC (2014).
} 
Even though one can think of a tenuous 'benefit' rationale for some such linkages - for instance, between tobacco taxes and expenditures attributable to lung cancer or those devoted to anti-smoking campaigns - the likelihood that the amount of money generated by this revenue source in any period will provide just the amount that a country should rationally be spending on such services is infinitively small. Only those who think that an additional scarce revenue dollar spent on increasing health spending is always and everywhere more socially beneficial than any other possible expenditure (or tax reduction) could possibly support the rigidity of tightly linking particular health expenditures to the amount of revenues that happen to be generated by particular taxes. In reality, even when excise taxes are earmarked to particular expenditures most such earmarking is 'loose' in the sense that even if the money from tax increases may be shown in the accounts as flowing into health expenditures, the amount of such expenditures is not necessarily affected by such accounting because the 'additional' revenues simply replace general budgetary funding. ${ }^{14}$ If more (or less) revenue from an earmarked tax does not mean a real increase (or decrease) in spending, the earmarking is illusory, not real. The reason is simple. Money is fungible and -- unless a particular revenue source is the only source of funding for a particular expenditure -- the result of increasing (or decreasing) collections from that source can always be offset by altering funding from other sources. A review of experience in various countries suggests that merely designating particular revenues for particular expenditures has had little discernible effect on how much is spent on those items (Bird and Jun 2007).

People may think they know how the money is going to be spent; but they do not. Indeed matters may be even worse than this because tying increased sin taxes to virtuous health spending - a measure that may at first appear to increase accountability by guaranteeing the taxpaying public that the increased funds will go to something that they demonstrably desire may obfuscate what is really going on and hence reduce than increase government accountability. It is unclear that those who wish to improve transparency and governance, even if they are also interested in improving health outcomes, should be happy with such earmarking.

\section{Conclusion}

Serious externalities are created by the consumption of tobacco and perhaps even more arise from excessive consumption of alcohol. Although it is beyond the limits of present knowledge in most

\footnotetext{
${ }^{14}$ For a more general discussion of different varieties of earmarking, see Bird and Jun (2007).
} 
developing countries to correct such problems to any significant extent by designing finely-targeted taxes on these products, international experience does provide some useful guidance for those who wish to do what they can to improve both revenue systems and social outcomes. Often, not only can more revenues be raised from this source with relative efficiency but doing so will reduce consumption and thus improve health outcomes. To get the best results in terms of both revenue and health, however, taxes on alcohol and tobacco should generally be imposed at specific rates imposed on the basis of alcohol and tobacco content and adjusted periodically for inflation. Those concerned with reducing the social costs of harmful consumption who wish to achieve such important supplementary objectives as reducing public drunkenness and drunk driving and preventing the immature from accessing tobacco and alcohol are better advised to pay close attention to the design and effectiveness of the accompanying regulatory system than to attempt to achieve such aims by designing more complex tax structures (Box 5). Similarly, since imposing high taxes on particular products creates substantial incentives for evasion by smuggling, illicit production, and simply fiddling the books, close attention must also be paid to strengthening and improving the administration of excise taxes.

Such conclusions may seem bland. But 'bland' in the sense of an effectively administered uniform specific excise structure is more likely to produce good results in most developing countries than trying to solve major social policy problems primarily through taxation or to fine-tune excise policy to the latest theoretical or empirical findings (which often apply to a quite different institutional setting). The main role of taxes on alcohol and tobacco, like all taxes, is to produce revenue to finance public activities in an acceptably efficient and equitable fashion. However, if these particular taxes are designed and implemented properly, and supported by an appropriate regulatory system, they also reduce the level of harmful consumption of these products, thus both producing revenue and improving health outcomes. Little more can be asked of any tax. 


\section{Box 1}

\section{Sin Tax Reform in the Philippines ${ }^{15}$}

In 2012, the Philippines passed a new Sin Tax Law (STL) increasing excise taxes on tobacco and alcohol products. The previous system, even after a major reform in 1997, suffered from a number of shortcomings. Cigarette excise taxation was greatly complicated by a long-standing 'tier' system under which lower price cigarettes attracted lower levels of taxation, thus reducing the cost of "entry level" cigarettes and weakening efforts to discourage smoking through increases in retail prices. A similar tier system applied to alcohol, with tier thresholds set so that domestic producers incurred lower excise rates while more expensive international brands attracted higher rates -a structure that was successfully challenged in the WTO as violating the principle of national treatment. In addition to the inherent protectionism of the tier system, in the case of cigarettes the grandfathering of rates for specific brands further protected incumbent producers and discouraged competition. Moreover, because excise taxation, already weakened by leakages arising from complex tax structures and fragmented oversight, was not adequately indexed to inflation, revenues from these taxes were eroding steadily, declining from $1.25 \%$ of GDP in 1997 to only $0.5 \%$ in 2012. In 2010, Philippine taxes on tobacco as a proportion of retail sales prices were the lowest in ASEAN with the exception of Cambodia (Box 2). Unsurprisingly, cigarette and alcohol consumption in the Philippines were higher than in most countries with similar levels of GDP per capita.

Since the government was under fiscal pressure and politically committed to increase social spending, the attraction of a reform that would increase revenues - the new STL is estimated to increase sin tax revenues by $60 \%$ once fully in effect - and reduce adverse health consequences from smoking and drinking was obvious. Moreover, such a reform would also serve to improve governance and transparency by leveling the competitive playing field and reducing the extent to which, through lobbying and regulatory capture, oligopolistic producers in both the tobacco and alcohol industries were able to shape policy. On the other hand, previous attempts at reform had failed repeatedly to overcome the combined opposition arising from producers (including regionally concentrated tobacco farmers), critics of the adverse effects of increased alcohol and tobacco taxes on the poor, and those who argued that increased smuggling and evasion was likely to offset much of the anticipated revenue gain.

To overcome such opposition, the reform was positioned as not only (1) as a way to offset increasing problems facing the existing excise taxes in terms of administration and revenue but also as (2) a measure that would both improve health outcomes by raising prices and curbing demand and also finance expanding health coverage to the poor and near-poor. In addition, the new system was both (3) phased in gradually in order to minimize the transitional costs to producers and consumers and (4) implemented through an elaborate and transparent accountability system intended to reassure people that the incremental funds were being properly targeted and spent. ${ }^{16}$ Finally, close attention was paid to designing the restructured tax system to come as close as politically possible to the 'health' ideal of a uniform indexed specific tax system discussed in the present paper. ${ }^{17}$

Although the new STL is obviously not totally free from the host of complexities and administrative problems that beset the Philippine fiscal system in general and may not be completely ideal from either

\footnotetext{
15 This note is based on the author's interpretation of material in World Bank (2014).

${ }^{16}$ Although most incremental funds are earmarked (for the first time) to health spending, the long-standing earmarking of some cigarette tax revenue to tobacco-producing regions persists. Of course, it remains to be seen if it will the rather complex accountability and monitoring structure envisaged in the STL can be fully and effectively implemented.

17 Unsurprisingly given the extensive political negotiations that inevitably accompany significant tax change, the final tax design might perhaps still be improved in some respects. In particular, the $4 \%$ annual indexing factor is at best a very rough way to maintain effective tax rates while spirits continue to have the lowest unit price of any alcohol - as has long been the case in the
} 
an economic or a health standpoint, it is clearly simpler, more transparent, and better in almost all respects than the previous system. The experience of the Philippines with 'sin' tax reform shows that with good design, careful marketing, and adequate political backing, even countries facing difficult and complex economic and political circumstances can sometimes take important steps down the road of fiscal reform. 


\section{Box 2}

\section{Taxes on Tobacco and Alcohol in ASEAN}

Taxes on alcohol and tobacco have declined significantly in terms of their revenue importance in many ASEAN countries over time both because of the rising importance of general taxes like VAT and the specific nature of many excise taxes. However, these taxes remain important sources of revenue in some countries in the region, as indicated in Table 1. Tobacco taxes, for example, provided $8.4 \%$ of total taxes in Indonesia in 2007 (Barber et al 2008) compared to 2.3\% in Thailand, where, however, taxes on alcohol provided another $4.6 \%$ (Bhoocha-oom 2009). As the table suggests, these taxes are of very varying importance in different countries.

\section{Table 1}

\section{Excise Tax Revenue in some ASEAN Countries (\%)}

\begin{tabular}{|l|l|l|l|l|l|l|}
\hline Country & $\begin{array}{l}\text { Taxes/GDP } \\
(2010)\end{array}$ & $\begin{array}{l}\text { Excises/Taxes } \\
(2010)\end{array}$ & $\begin{array}{l}\text { Excises/Taxes } \\
(2000)\end{array}$ & $\begin{array}{l}\text { Excises/Taxes } \\
(1976)\end{array}$ & $\begin{array}{l}\text { Tobacco } \\
\text { Tax/Taxes } \\
(1976)\end{array}$ & $\begin{array}{l}\text { Alcohol } \\
\text { Tax/Taxes } \\
(1976)\end{array}$ \\
\hline Cambodia & 8.2 & 17.1 & 16.3 & & & \\
\hline Indonesia & 12.3 & 10.3 & 6.4 & 4.6 & 3.9 & 0.2 \\
\hline Lao DPR & 13.3 & 22.8 & 18.7 & & & \\
\hline Malaysia & 16.5 & 7.1 & 10.5 & 10.0 & 0.7 & 1.5 \\
\hline Philippines & 14.2 & 5.9 & 12.9 & 15.9 & 4.7 & 1.9 \\
\hline Thailand & 16.5 & 20.7 & 25.6 & 22.2 & 7.5 & 6.7 \\
\hline Vietnam & 21.5 & 9.3 & 8.8 & & & \\
\hline
\end{tabular}

Notes: The data in this table have been compiled from a number of not fully compatible sources Years shown are approximate and the nature of some taxes has changed substantially over time: for example, initially imports were not subject to excise duties in some countries.

Sources: IMF GFS, Cnossen (2007), and Asher and Booth (1983).

There is also little similarity between the detailed structure of alcohol and tobacco taxes across countries in the region - something that other studies have also found to be true in other regions. ${ }^{18}$ Although excise rate structures are difficult to compare owing to their detailed and often specific nature, a simplified comparison shown in Table 2 depicts wide variations in the level of taxation in different countries. Although most countries in the region have increased their rates to some extent and some have altered the structure of these taxes in recent years, there has been little convergence in either respect. Comparison of Asher and Booth (1983), Cnossen (2007) and World Bank (2014) suggests that the divergences between countries In the importance and structure of alcohol and tobacco taxes have not altered much over the years. Wide differences in tax structure remain with one, the other, or both tobacco and alcohol being taxed (in addition to the general VAT) by special excise taxes on either an ad valorem or a specific rate basis or in some cases a composite ad valorem and specific system.. The tax bases also differ from country to country. Ad valorem taxes like those in Cambodia and Vietnam are based on ex-factory price (or CIF + import duty for imports). However, Thailand uses the 'last wholesale' price and the Philippines 'net retail price' (i.e. sales price excluding VAT and excise) based on a survey of retail outlets. Indonesia also uses prices to distinguish different specific rate classes. Singapore (not

\footnotetext{
${ }^{18}$ For example, see Bird and Wallace (2010) on sub-Saharan Africa and O'Hagan and Riley (2005) on Europe.
} 
shown in Table 2), like the Philippines, imposes only specific rates on cigarettes, while Thailand, Cambodia, and Vietnam levy ad valorem rates and Malaysia has a hybrid system.

Table 2

Characteristics of Excise Tax Systems in some ASEAN Countries, 2012

\begin{tabular}{|c|c|c|c|c|}
\hline Country & $\begin{array}{l}\text { Excise on } \\
\text { 'Representive' } \\
\text { Cigarettes } \\
\text { (\% of Philippine } \\
\text { Rate) }\end{array}$ & $\begin{array}{l}\text { Cigarette } \\
\text { Tax }\end{array}$ & $\begin{array}{l}\text { Excise on } \\
\text { 'Representative' } \\
\text { Beer } \\
\text { (\% of Philippine } \\
\text { Rate) }\end{array}$ & $\begin{array}{l}\text { Beer } \\
\text { Tax }\end{array}$ \\
\hline Cambodia & 17 & $10 \%$ & 195 & $25 \%$ \\
\hline Indonesia & $\begin{array}{l}109-167 \text { (depending } \\
\text { on production } \\
\text { Capacity\} }\end{array}$ & $\begin{array}{l}\text { Specific rate depending on } \\
\text { production } \\
\text { capacity and retail sales price }\end{array}$ & 490 & Specific \\
\hline Lao PDR & $\begin{array}{l}53 \text { (but } 382 \text { for } \\
\text { imports) }\end{array}$ & $\begin{array}{l}\text { Specific rates varying with } \\
\text { production cost (domestic) or } \\
\text { import }\end{array}$ & 390 & $50 \%$ \\
\hline Malaysia & 267 & $20 \%+$ specific tax & 1122 & $\begin{array}{l}15 \%+ \\
\text { specific }\end{array}$ \\
\hline Thailand & 191 & $85 \%$ & 460 & $\begin{array}{l}\text { Specific } \\
\text { or } 60 \%\end{array}$ \\
\hline Vietnam & 109 & $65 \%$ & 347 & $25 \%$ \\
\hline
\end{tabular}

Notes: 'Representative' products are for purposes of comparison only and not necessarily representative of the products actually consumed in the different countries.

Source: Preece (2015)

The level and structure of taxes on alcohol and tobacco continues varies widely across the region, reflecting both different national traditions and the complex factors discussed in the present paper that shape taxation of these products. In addition to the recent Philippine reform (Box 1), Thailand, in addition to introducing 'surcharges' on beverages with higher alcohol strength, restructured its taxes on alcohol in 2013, moving from 'greater of' an ex-factory ad valorem calculation and specific rate calculation to a mixed system in which an ad valorem component is calculated against a 'Last Whole Price' and a specific rate comprising the greater of 'per litre' or 'per litre of alcohol' rate. Indonesia increased its alcohol taxes significantly in 2009 and raised its rates on tobacco in 2012 and again on alcohol in 2014. 


\section{Box 3}

\section{Taxing Alcohol and Tobacco in the United Kingdom: The Uses and Limits of the Economic Approach}

The recent 'Mirrlees Report' (Institute for Fiscal Studies 2011) in the UK provides an excellent example of the uses and limits of the economic approach to designing excise taxes on alcohol and tobacco. In the UK, such taxes are not unimportant, accounting for about 3.5 percent of tax revenue and a bit over 1 percent of GDP. The rationale for these taxes and their appropriate level and design are considered in detail in one of the staff reports (Crawford, Keen and Smith 2010, hereafter CKS), underlying the Mirrlees Report. While, as CKS (2011, p. 354) stress, it is unlikely that estimates from one country can be carried over without modification to another country or that externalities - which are affected both by institutional arrangements and cultural contexts - are uniform across countries, the main conclusions reached by CKS after a thorough review of the recent theoretical and empirical literature on the structure and effects of taxing tobacco and alcohol are as follows:

- The key factor relevant to the revenue-raising efficiency of product taxes (the OTR approach) is not their own-price elasticity - the focus of the revenue-maximization approach (RMTR) mentioned in the present paper - but rather how complementary or substitutable they are with leisure. Since the best empirical studies of the relation between tobacco and alcohol consumption and the labor/leisure choice so far carried out in developed countries suggest that this relation is complex and unclear, there is no compelling case for above-average taxation of these products in terms of efficiency.

- In contrast, a good case can be made for externality-correcting taxation of tobacco and 'abusive' alcohol consumption. Identifying, measuring and determining the correct level of such taxation with respect to tobacco is a complex issue that requires resolving such difficult and often controversial issues as the location and significance of the boundary between internalized and external costs, the treatment of costs borne by family members, the treatment of healthcare costs when partly financed by publicly funded care, and the correct way to deal with effects on wages and productivity. Much the same issues arise with respect to designing excises on alcohol with the additional complication that most abuses in this case arise from excessive consumption and the marginal external cost may well be very different from the average. Nonetheless, particularly when such behavioral issues as time inconsistency and lack of self-control are considered, CKS conclude that some 'extra' taxation of these products is likely justified on externality grounds but that existing research does not provide any clear guidance as to the appropriate level of such taxation.

- Finally, with respect to specific vs. ad valorem taxation of 'sin' taxes, CKS note that once again the choice is difficult because it depends importantly on the structure of consumer preferences and on market structure - both matters about which we seldom have adequate information to permit fine-tuned conclusions. However, on the whole they conclude that the advantages of specific taxes in terms of administrative simplicity, more stable revenues, and being more closely targeted to the externality to be corrected likely outweigh the advantages of ad valorem taxes in terms of distributional impact and dealing with monopolistic suppliers. 


\section{Box 4}

\section{The Choice of Tax Base}

When specific rates are applied to tobacco products, the tax base may be the number of units (package or stick) or the weight of tobacco, with possible differentiation between tobaccos of different quality (or harmfulness). European Union (EU) rules require member states to impose cigarette excises with both ad valorem and specific components, with the latter based on the number of units and constituting between 5 and 55 percent of the total tax. To comply with these rules, the UK changed from the weight basis to the number of units, a move that reportedly impacted the pattern of competition in the industry (Crawford, Keen and Smith 2010). From a public health perspective, it would seem more appropriate to tax the harmful content (tar, nicotine, carbon monoxide). However, some evidence suggests that the impact of doing so may be offset by smokers smoking weaker cigarettes more intensively by inhaling harder or smoking further down the length e.g. to the filter (Adda and Cornaglia 2006; Evans and Farrelly 1998).

Along the same lines, the most appropriate base for the taxation of alcohol is presumably the alcohol content. In most countries, some forms of consumption are taxed more heavily than others, with taxes per unit of alcohol often being considerably higher on distilled spirits than on beer or wine. The base of specific taxes on alcohol may be alcohol content or the size or volume of the container. There is also often substantial differentiation in terms of tax per unit of alcohol on different varieties within each of these three major categories. Uniform taxation on the basis of alcohol content is a simple and appealing rule (Crooks 1989). However, if consumption of some forms of alcoholic beverage are considered to generate greater external costs than others - for example, if beer is seen as the drink that is most likely to lead youths down the path to alcoholism or if spirits (whether 'mixed' or not) are considered to be the main way for 'binge' drinkers get drunk quickly - some differentiation may be considered desirable on public health grounds. Similarly, if imposing high taxes on 'legal' alcohol is likely to lead abusers to consume illicit and often dangerous alternatives, such concerns may suggest that what is needed is not so much higher taxes as better enforcement of existing taxes and a better regulatory structure (see Box 5). 


\section{Box 5}

\section{Regulating Smoking and Excessive Drinking}

"Excise duties, whether specific or ad valorem, are not the only and often not the best instrument to influence the behavior of smokers [and] drinkers....Depending on circumstances, regulations are an appropriate alternative ... a tobacco tax cannot deal in a cost effective way with the effects of passive smoking....the alcohol excise is an inadequate instrument to restrain people from getting behind the wheel of their car after they have had a drink."19

Restrictions on smoking - once an acceptable and widespread social activity - are now almost world-wide. It is increasingly common to ban smoking in certain establishments (e.g. restaurants, public buildings, offices, stores) or even in any public place or at the extreme even in private spaces like automobiles when children are present. The sale of cigarettes is sometimes limited to certain types of outlet and restricted to buyers older than some specified age. Many countries also have a minimum age for the sale and consumption of alcohol as well as restrictions on who can sell alcohol and when they can sell it and maximum acceptable blood-alcohol levels for defining drunk drivers. Penalties - fines, loss of sale privileges, even imprisonment in some cases - may be imposed for noncompliance with the regulations. Regulations aimed at curbing smoking and the abuse of alcohol (and how effectively they are enforced) need to be taken into consideration in designing and administering taxes on tobacco and alcohol. For example, can taxes ever be set high enough to squeeze out the serious social harms associated with drunk driving? Or does the persistence of accidents due to alcohol suggest that a better approach may be stricter enforcement of existing laws? How best can regulations and taxes work together to achieve the objectives of reducing the social costs associated with smoking and drinking?

Tentative answers to some of these questions are just beginning to emerge even in developed countries. Empirical results on the impact of regulations on alcohol consumption and the associated externalities (drunk driving in particular) are mixed. For younger alcohol consumers, Grossman et al. (1994) find that a higher drinking age does reduce consumption to the point that motor vehicle deaths decline. Benson, Mast and Rasmussen (1999) find that U.S. laws establishing minimum drinking ages and prohibiting driving with open containers of alcoholic beverages are effective deterrents to drunk driving but only when taxes on alcoholic beverages are also present. In a study of drunk-driving, prices, and excise taxation in the U.S., Young and Bielinska-Kwapisz (2002) found that regulations like open container laws and drinking age restrictions act as complements to taxes in reducing fatalities from drunk driving. While there as yet seems to be little consideration of such questions in developing countries, as WHO (2001) stresses most developing countries seldom have sufficient resources to administer such regulations effectively. Nonetheless, as WHO (2004) argues, what matters from a public health perspective is less the impact of any one policy - such as excise taxation - than the joint impact of all policies - taxation, information and education, and regulation.. Similarly, from an economic perspective, as Christiansen and Smith (2009) show, over a wide range of market conditions and externalities the 'right' combination of tax and regulatory policy is likely to produce better results than either policy will on its own. While such arguments seem both plausible and likely correct, the problem in most countries is, as emphasized elsewhere, that they simply do not have the information needed to establish the best mix of tax and regulatory policies. Nonetheless, although both tax and regulatory instruments are inevitably going to be imperfect and inadequate, a combination of both is perhaps more likely to improve health outcomes. Those charged with designing and implementing sin taxes must therefore pay close attention to the nature and effectiveness of the regulatory environment as well as the local cultural context.

${ }^{19}$ Cnossen (2010), p. 241. 


\section{References}

Adda, J. and F. Cornaglia (2006) "Taxes, Cigarette Consumption, and Smoking Intensity," American Economic Review, 96 (4): 1013-1028.

Asher, M. and A. Booth (1983) Indirect Taxation in ASEAN (Singapore University Press).

Barber, S. et al. (2008) Tobacco Economics in Indonesia, available at http://www.worldlungfoundation.org/ht/a/GetDocumentAction/i/6567 (consulted 10 July 2014).

Barzel, Y. (1976) "An Alternative Approach to the Analysis of Taxation," Journal of Political Economy, 84 (6): 1177-1197.

Benson, B., B. Mast, and D. Rasmussen (1999) "Deterring Drunk Driving Facilities: An Economics of Crime Perspective," International Review of Law and Economics, 19 (2): 205-225.

Bhoocha-oom, A. (2009) Alcohol Excise Taxation of Thailand, Presentation to Asia Tax Forum Workshop, Bangkok, November.

Bird, R. and J. Jun (2007) "Earmarking in Theory and Korean Practice," in S. Phua, ed., Excise Taxation in Asia (Centre for Commercial Law Studies, Faculty of Law, National University of Singapore)

Bird, R. and S. Wallace (2010) Taxing Alcohol in Africa: Reflections and Updates, Public Policy Working Paper 1031, International Center on Public Policy, Andrew Young School of Public Policy, Georgia State University.

Bosch, A. and S.Koch (2014) Using a Natural Experiment to Examine Tobacco Tax Regressivity, Working Paper, Department of Economics, University of Pretoria, May.

Brezis, M. and R. Marans (2010) "Do People Support Sin Taxes? A Population Survey of Attitudes," World Medical \& Health Policy, 2 (4), Article 4.

Chiou, L. and E. Muehlegger (2014) "Consumer Response to Excise Tax Changes," National Tax Journal, 67 (3): 621-650.

Christiansen, V. and S. Smith (2009) Externality-correcting Taxes and Regulation, Working Paper 09/06, Institute for Fiscal Studies, London.

Cnossen, S. (2007) "The Role and Rationale of Excise Duties in the ASEAN Countries," in S. Phua, ed., Excise Taxation in Asia (Centre for Commercial Law Studies, Faculty of Law, National University of Singapore)

Cnossen, S. (2008) "Do Drinkers Pay Their Way in the European Union?" Finanzarchiv/Public Finance Analysis, 64 (4): 508-39.

Cnossen, S. (2010) "Excise Taxation in Australia," in Melbourne Institute, Australia's Future Tax and Transfer Policy Conference (Melbourne: Melbourne Institute of Applied Economic and Social Research)

Cnossen, S. and M. Smart (2005) "Taxation of Tobacco," in S. Cnossen, ed., Theory and Practice of Excise Taxation: Smoking, Drinking, Gambling, Polluting, and Driving (Oxford: Oxford University Press)

Cook, P. (2007) Paying the Tab: The Economics of Alcohol Policy (Princeton NJ: Princeton University Press). 
Cooper, A. (2007) "The Affordability of Cigarettes in ASEAN Countries: Implications for Tax Policy," in S. Phua, ed., Excise Taxation in Asia (Centre for Commercial Law Studies, Faculty of Law, National University of Singapore)

Crawford, I., M. Keen and S. Smith (2010) "Value Added Tax and Excises," in Institute for Fiscal Studies, Dimensions of Tax Design: The Mirrlees Review (Oxford: Oxford University Press).

Crooks, E. (1989) Alcohol Consumption and Taxation, IFS Report Series No. 34, Institute for Fiscal Studies, London.

Dalhby, B. (2008) The Marginal Cost of Public Funds: Theory and Applications (Cambridge, MA: MIT Press).

Evans, W. and M. Farrelly (1998) "The Compensating Behavior of Smokers: Taxes, Tar and Nicotine," RAND Journal of Economics, 29: 578-595.

Grossman, M. et al (1994), "Effects of Alcohol Price Policy on Youth," Journal of Research on Adolescence, 4(2): 347-364.

Gruber, J. (2010) "Commentary" in Institute for Fiscal Studies, Dimensions of Tax Design: The Mirrlees Review (Oxford: Oxford University Press).

Haavio, M. and K. Kotakorpi (2011) "The Political Economy of Sin Taxes," European Economic Review, 55: 575-594.

Institute for Fiscal Studies (2011) Tax by Design: The Mirrlees Review (Oxford University Press).

International Tax \& Investment Center (ITIC) and Oxford Economics (2013) Are Earmarked Taxes on Alcohol and Tobacco a Good Idea? Evidence from Asia, Special Report, November, available at http://www.iticnet.org/publications/studies-and-reports/year/2013 (consulted January 23, 2015)

International Tax \& Investment Center and Oxford Economics (2014) The Importance of Fiscal Sovereignty in Tobacco Taxation, Special Report, September, available at http://www.iticnet.org/images/COP6SpecialReport.pdf (consulted January 5, 2015).

Keen, M. (1998), "The Balance between Specific and Ad Valorem Taxation," Fiscal Studies, 19 (1): 1-37.

Nelson, J. (2014) Binge Drinking, Alcohol Prices, and Alcohol Taxes, AAWE Working Paper No. 146, American Association of Wine Economists, January.

O’Donoghue, T. and M. Rabin (2006) “Optimal Sin Taxes," Journal of Public Economics, 90: 1825-1849.

O'Hagan, J. and A. Reilly (1995) "The Taxation of Alcoholic Beverages," in C. Sandford, ed., More Key Issues in Tax Reform (Bath UK: Fiscal Publications).

Preece, R. (2015) "Excise Taxation of Key Commodities across South East Asia: A Comparative Analysis ahead of the ASEAN Economic Community in 2015," World Customs Journal, 6 (1): 3-16.

Smith, S. (2005) "Economic Issues in Alcohol Taxation," in S. Cnossen, ed., Theory and Practice of Excise Taxation: Smoking, Drinking, Gambling, Polluting, and Driving. (Oxford: Oxford University Press),

Sunley, E. (2007) Tobacco Taxation in Asia: Recent Trends and Developments, Paper presented at Fourth Meeting of the Asia Tax Forum, Hanoi, April. Available at http://www.iticnet.org/file/document/watch/119 (consulted January 5, 2015). 
Usher, D. (2014) How High Might the Revenue-Maximizing Tax Rate Be? Queen's Economic Department Working Paper QED No. 1334, December.

World Bank (2014) Philippines: Delivering Successful Sin Tax Reform.

World Health Organization (2001) Global Status Report on Alcohol [available at http://www.who.int/substance abuse/publications/alcohol/en/

World Health Organization (2004) Global Status Report on Alcohol [available at http://www.who.int/substance abuse/publications/alcohol/en/

World Health Organization (2011) Technical Manual on Tobacco Tax Administration.

Young, D. and A.Bielinska-Kwapisz (2002), "Alcohol Taxes and Beverage Prices," National Tax Journal, 55 (1): 57-73. 